\title{
Lone Star vs creationism
}

\section{The battle against anti-scientific literalism continues. Next stop Texas.}

T he creation-evolution debate in the United States is ever-changing: any given week might bring good news for science advocates in some states, but bad news in others. At the moment, the good news is coming from Florida, which on 19 February voted to adopt new science standards that significantly strengthen the role of evolution in the state's biology curriculum (see page 1041).

But the next round of news will undoubtedly come from Texas, where a state agency faces a decision whose ramifications could resonate across the United States for years to come. The Texas Higher Education Coordinating Board is considering an application by the Institute for Creation Research (ICR) to grant online master's degrees in science education. And an advisory panel to the board has recommended that Texas should accept the application.

The ICR accepts the Bible as literal truth on all topics. According to its website, the palaeoclimatology class covers "climates before and after the Genesis Flood". Anatomy lab includes "limited discussion of embryology and accompanying histology, specifically in regards to evolutionary theory and its alternative - the creation of fully functional major groups of animals".

For most of its existence the ICR was ensconced in the San Diego area, but in 2007 it relocated to Dallas, in an apparent move to expand its national reach. California may have been glad to see it go; the state had been battling the ICR over accreditation since 1981, when, under a sympathetic official, the institute first got the go-ahead to offer degrees. But in Texas the ICR must win approval from the state board to continue setting up its graduate programmes before seeking permanent accreditation.

The decision falls to the nine-member higher-education board. It had been expected to vote on the issue in January, but instead asked the ICR for more information - about the research done by its faculty members, about how an online course would teach experimental science, and about why its curriculum is so different from other degree-granting institutions in science education. A vote is expected at the board's 24 April meeting.

High-powered scientists in Texas are already weighing in, asking board commissioner Raymund Paredes to deny accreditation. And there are signs that the board is listening. In a response to Nobel laureate Steven Weinberg, Paredes wrote that "our primary criterion will be how the proposed program will contribute to preparing high school students to do rigorous science in higher education". One can only hope such rational approaches will outweigh the primary ICR reaction, which has been to send out a call for prayer.

Scientists in Texas and the rest of the country must continue to make it clear to Paredes why the board should deny accreditation to this organization. The ICR has managed to con its way into the California educational system for decades. Texas must not succumb as well.

\section{Time to take control}

\section{With money now flowing in, the fight against malaria must shift from advocacy to getting results.}

//7 he billion-dollar malaria effort is flying blind," declares Mark Grabowsky in a Commentary on page 1051 of this issue. And given that Grabowsky is malaria coordinator of the Global Fund to Fight AIDS, Tuberculosis and Malaria, which disburses almost half the US $\$ 1$ billion spent annually on malaria control, we might do well to listen.

Grabowsky argues that, above all, malaria control requires data: to assess the present situation, to target control measures and to evaluate their effectiveness. He also says that an adequate surveillance programme would cost as little as $\$ 10$ million a year. Yet that money has not been forthcoming; malaria managers still lack even the most rudimentary information (see Nature doi:10.1038/news.2008.621; 2008).

The surveillance problem is symptomatic of a wider failure in basic project management. The 'international' malaria effort is actually a hotch-potch of fragmented, country-level projects funded by multiple donors, with little regional and international coordination. Such leadership would normally be provided by the World Health Organization (WHO), as it has done to great effect in the fight against measles and polio. But the WHO-led Roll Back Malaria initiative is mired in bureaucracy and anything but effective (see Nature 430, 935; 2004).

That management problem, in turn, reflects a still deeper issue: the agencies involved in the malaria fight, including the WHO, have for too long been driven largely by advocacy. It's true that advocacy was a supreme need a decade ago, when malaria control was off the radar and gathering a mere $\$ 100$ million a year. But that mindset has persisted even as the funding has multiplied tenfold.

Take the good news spin put on recent studies showing that bed nets and drugs cut the malaria burden by as much as half in Zanzibar, Ethiopia and Rwanda. That sounds dramatic. But it's hardly unexpected, as the low malaria transmission rates in these countries make the disease comparatively easy to control. And in the meantime, silence surrounds the lack of a single win in high-transmission areas such as the Democratic Republic of the Congo or Nigeria, which account for half the malaria mortality in Africa.

Yes, on-the-ground conditions are difficult, as is reported in Zambia, the flagship of international efforts (see page 1047). But the international malaria effort is still geared towards maintaining donor support instead of getting teams into the field gathering data and delivering basic items such as bed nets. That's why almost no country is near to meeting Roll Back Malaria's target of having $80 \%$ coverage with bed nets and drugs by 2010; why malaria is still killing more than 1 million people every year; and why the global control effort is way off track to meet the internationally agreed goal of halving malaria deaths by 2010 .

Such goals are undeniably ambitious. But they are a spur to action - and in line with what the WHO has already achieved with measles and polio. What the malaria effort urgently needs now is leadership, and a shift from spin to substance and results. 